\title{
MENINGKATKAN KOMPETENSI PROFESIONAL GURU SEKOLAH DASAR MELALUI PUBLIKASI KARYA ILMIAH PADA JURNAL ELEKTRONIK
}

\section{Dede Salim Nahdi*, Dadang Sudirno, Mohamad Gilar Jatisunda, Ujiati Cahyaningsih, Abdur Rasyid, Ipin Aripin, Yoyo Zakaria Ansori, Hani Sri Mulyani}

\author{
Universitas Majalengka \\ *salimnahdi@unma.ac.id
}

\begin{abstract}
Professionalism is a competency that must be owned by a teacher. Teacher professionalism is required to continue to develop in accordance with the times, science, and community needs including the need for quality human resources and have the capability to be able to compete in regional, national, and international forums. One form of teacher professional development is to write scientific papers. Through scientific writing, teachers can improve their writing skills, train themselves to be able to integrate several ideas and present them systematically. However, most teachers are not fully aware of the importance of publication for their scientific papers. This is reflected in the still low competence of teachers, especially in the aspect of professionalism. This condition motivates service implementers to carry out scientific publication training activities for teachers. This service activity aims to provide training to teachers about publishing scientific papers in electronic journals. The methods that will be used in this program are seminars, discussions, and training methods. From the results of this community service activity, it was found that there was an increase in teachers' understanding of electronic journals, and being able to carry out the process of scientific publication in electronic journals.
\end{abstract}

Keywords: professional competence; publication of scientific papers; electronic journal; teacher

\begin{abstract}
Abstrak
Profesionalisme merupakan kompetensi yang wajib dimiliki seorang guru. Profesionalisme guru dituntut agar terus berkembang sesuai dengan perkembangan jaman, ilmu pengetahuan, serta kebutuhan masyarakat termasuk kebutuhan terhadap sumber daya manusia yang berkualitas dan memiliki kapabilitas untuk mampu bersaing baik di forum regional, nasional, mapupun internasional. Salah satu wujud pengembangan keprofesian guru adalah dengan menulis karya ilmiah. Melalui karya tulis ilmiah guru dapat meningkatkan keterampilan menulisnya, melatih diri untuk dapat mengintegrasikan beberapa ide serta menyajikannya secara sistematis. Namun kebanyakan guru belum sepenuhnya menyadari tentang pentingnya publikasi untuk karya tulis ilmiahnya. Hal ini tercermin dari masih rendahnya kompetensi guru, khususnya pada aspek profesionalisme. Kondisi inilah yang memotivasi pelaksana pengabdian untuk melaksanakan kegiatan pelatihan publikasi ilmiah pada guru. Kegiatan pengabdian ini bertujuan untuk memberikan pelatihan kepada guru tentang publikasi karya ilmiah pada jurnal elektronik. Metode yang akan digunakan dalam program ini adalah metode seminar, diskusi, dan pelatihan. Dari hasil kegiatan pengabdian masyarakat ini, diperoleh hasil adanya peningkatan pemahaman guru tentang jurnal elektronik, dan mampu melakukan proses publikasi ilmiah pada jurnal elektronik.
\end{abstract}

Kata Kunci: kompetensi profesional; publikasi karya ilmiah; jurnal elektronik; guru

\begin{tabular}{l|l|l} 
Submitted: $2021-04-02$ & Revised: $2021-04-25$ & Accepted: $2021-04-30$
\end{tabular}

\section{Pendahuluan}

Guru akan senantiasa dituntut melakukan pengembangan kompetensi profesionalnya secara berkelanjutan untuk menunjang kompetensi diri dan karirnya di masa depan (Mustofa, 2007; Rusdarti, et al, 2019). Pengembangan yang dilakukan guru juga akan berdampak pada peningkatan aspek yang lain, seperti peningkatan jabatan fungsional dan angka kredit. Guru akan mampu melaksanakan tugasnya dengan baik jika memiliki tingkat profesionalisme tertentu yang terlihat dari kompetensi, kemahiran, kecakapan, atau keterampilan yang sesuai dengan parameter mutu tertentu (Danim, 2010; Latiana, 2019).

Guru profesional dapat menjalankan fungsi utamanya dengan efektif serta efisien dalam menjalankan kegiatan pembelajaran yang berkualitas sehingga tercapai tujuan pendidikan nasional (Nidawati, 2020). Guru akan terus dituntut untuk meningkatkan mutu pembelajaran di kelas dengan berbagai solusi, seperti pengembangan perangkat pembelajaran ataupun perbaikan proses 
dan hasil pembelajaran (Yolenta Owa, 2021). Hal ini dapat dicapai guru melalui peningkatan kompetensi pedagogik dan profesional dengan melakukan penelitian dan menulis karya ilmiah (Suandi, 2008). Penulisan artikel ilmiah semacam ini diyakini dapat meningkatkan kemampuan profesionalisme guru sekaligus memperbaiki kualitas pembelajaran yang disampaikannya (Al Idrus, dkk., 2020). Namun mayoritas guru tidak menyadari pentingnya membuat karya tulis ilmiah dalam rangka pengambangan diri mereka (Muhali, dkk., 2019). Guru yang terbiasa menulis akan berdampak pada wawasannya dalam mengidentifikasi masalah-masalah pembelajaran di kelas sehingga tulisan ilmiah yang dibuat bermanfaat untuk pengambangan diri (Noorjannah, 2014). Sedangkan karya tulis yang diterbitkan (artikel jurnal) akan memberikan kontribusi terhadap peningkatan kualitas proses pembelajaran di sekolah, perkembangan ilmu pengetahuan dan pengembangan dunia pendidikan secara umum (Lestari, dkk., 2018). Sebagai seorang pendidik, guru tentu mengetahui data serta permasalahan yang dapat digunakan sebagai sumber dan bahan tulisan. Dengan tulisan tersebut, guru dapat mengidentifikasi masalah dan menemukan solusi untuk menyelesaikan masalah tersebut (Gunawan, dkk., 2018). Selain itu, dalam peningkatan karir, menulis karya ilmiah merupakan syarat mutlak bagi guru yang harus dipenuhi (Sumartini, Mulyani, Nugroho, 2019).

Namun tuntutan untuk menulis karya ilmiah, ternyata tidak sepenuhnya direspon secara positif oleh para guru. Banyak guru yang mengalami kesulitan dalam menulis karya ilmiah berupa artikel jurnal. Kondisi ini tercermin dari masih banyaknya guru yang tertahan pada golongan IVa. Hal ini terjadi karena kenaikan pangkat/jabatan pada Pembina/IVa ke atas diwajibkan memenuhi angka kredit dari pengembangan profesi minimal 12 kredit, yang di dalamnya harus membuat artikel jurnal ilmiah (Ilfiandra, dkk., 2016). Beberapa alasan penyebab rendahnya motivasi menulis karya ilmiah ini adalah ketakutan dan atau kecemasan menulis terkait dengan prosedur dan kriteria tulisan yang dapat diterima dan dihargai sebagai karya ilmiah (Yulhendri, Marna, \& Oknaryana, 2018). Sebagian terbesar guru menyatakan bahwa prosedur pembuatan karya ilmiah dan kriteria itu terlalu sulit untuk mereka penuhi atau ikuti. Mereka menyatakan belum mempunyai waktu untuk menulis, dan mencari sumber-sumber referensi sebagai rujukan. Mereka juga tidak tahu bagaimana cara untuk mempublikasikan karya ilmiah tersebut.

Budaya menulis memang masih sulit diterapkan pada semua guru hampir di seluruh Indonesia, termasuk guru-guru SD di Kabupaten Majalengka. Hal inilah yang menjadikan banyak guru SD di Majalengka terganjal kenaikan pangkat karena kesulitan dalam membuat karya tulis. Beberapa guru bahkan rela mengeluarkan biaya besar untuk membayar jasa pembuatan artikel jurnal ilmiah. Kondisi ini dikeluhkan Bupati Majalengka saat ini, Dr. H. Karna Sobahi, "Saat ini banyak guru yang kesulitan dalam membuat karya ilmiah. Bahkan terkadang mereka terpaksa meminta bantuan orang lain dalam membuatnya" (Jabarnews). Kondisi ini tentu harus segera dibenahi, karena budaya menulis sangat penting guru, selain untuk pengembangan pribadinya, budaya menulis juga akan berdampak pada berhasilnya tujuan pendidikan.

Rendahnya kemampuan guru SD di Majalengka dalam membuat artikel jurnal ilmiah berdampak pada rendahnya kompetensi guru, khususnya pada aspek pedagogik dan profesional. Rendahnya kompetensi guru SD tersebut tercermin dalam hasil Uji kompetensi Guru (UKG). Ratarata hasil Uji Kompetensi Guru (UKG) SD kabupaten Majalengka pada aspek pedagogik dan profesional hanya memperoleh skor 56,47 dan berada di bawah rata-rata hasil UKG SD provinsi Jawa Barat sebesar 56,65 bahkan jauh di bawah rata-rata nilai minimal lulus sebesar 80 . Kondisi tersebut tentu sangat memprihatinkan mengingat peran guru dalam upaya membangun mutu sumber daya manusia sangat krusial.

Ketika melakukan observasi ke beberapa sekolah dasar di Majalengka, tim pelaksana pengabdian masyarakat menemukan banyak informasi terkait permasalah yang mereka hadapi, Selain banyak guru SD yang terganjal dalam kenaikan pangkat/golongan, mereka juga memiliki keterbatasan dalam menulis karya ilmiah, seperti keterbatasan informasi dan waktu dalam 
mempelajari karya ilmiah. Kondisi ini berdampak pada pemahaman guru dalam menulis karya ilmiah dan bagaimana mempublikasikan karya tulis ilmiah hasil penelitiannya.

Dengan banyaknya permasalahan yang dihadapi guru, penulis memandang perlu adanya sebuah pelatihan kepada guru untuk melatih kemampuan menulis secara profesional. Kegiatan pendampingan penulisan artikel sangat efektif untuk meningkatkan pemahaman guru tentang jenis-jenis karya ilmiah, seperti artikel jurnal dan prosiding (Fatah, dkk., 2015). Atas dasar itulah pengusul termotivasi untuk melaksanakan kegiatan pengabdian Masyarakat dengan memberikan pelatihan kepada guru SD di Majalengka agar mampu mempublikasikan karya tulis ilmiahnya dengan harapan para guru tersebut dapat mengembangkan kompetensi profesionalnya

\section{Metode}

Kegiatan pengabdian ini dilaksanakan di Majalengka Jawa Barat dengan sasaran para guru Sekolah Dasar (SD). Dengan kegiatan ini diharapkan guru dapat membuat karya tulis ilmiah penelitian dan menerbitkannya pada jurnal online berbasis Open Journal System (OJS). Untuk tujuan tersebut pengusul menggunakan pendekatan seminar, diskusi, dan pelatihan.

Kegiatan sosialisasi yang dilaksanakan berupa pemamparan materi tentang Jurnal elektronik dan tips memilih jurnal yang tepat untuk tujuan publikasi. Di samping pemaparan materi melalui seminar, kegiatan ini juga menggunakan metode diskusi. Pada kegiatan diskusi ini, guru diberikan kesempatan untuk bertanya kapada narasumber terkait materi yang disampaikan. Diskusi dilakukan agar peserta lebih memahami materi yang telah disampaikan. Pada kegiatan ini, peserta juga dilatih untuk menulis karya ilmiah. Kegiatan pelatihan ini fokus pada strategi menulis artikel ilmiah sesuai dengan standar jurnal ilmiah elektronik dan juga akan memberikan informasi mengenai jurnal-jurnal yang dapat diakses, baik untuk rujukan (referensi) dan/atau untuk diajukan artikel ilmiah agar dimuat di jurnal tersebut.

Evaluasi pelaksanaan program dilakukan selama periode kegiatan program berlangsung serta di akhir kegiatan. Evaluasi ini dilakukan untuk mengetahui hasil dan progress dari pelaksanaan program yang telah direncanakan, serta untuk mengevaluasi daya serap peserta terhadap materi yang telah diberikan atau tingkat ketercapaian dari pelatihan yang telah diberikan. Evaluasi ini dilakukan dengan cara membandingkan kondisi guru sebelum pelaksanaan program dan kondisi setelah pelaksanaan program.

\section{Hasil dan Pembahasan}

Kegiatan pelatihan pada pengabdian ini dilaksanakan secara daring dengan konsep webinar. Hal ini dikarenakan adanya pandemi Covid-19 yang masih mewabah di Majalengka dengan status Zona Merah sehingga dengan alasan keamanan, pemerintah kabupaten Majalengka melarang melakukan kegiatan yang menyebabkan berkumpulnya orang dalam jumlah banyak.

Pada kegiatan pengabdian ini peserta yang mengikuti berjumlah 124 orang yang terdiri dari para guru sekolah dasar dan sekolah menengah. Undangan kegiatan webinar ini didistribusikan melalui aplikasi media sosial seperti whatsapp, Facebook, dan instagram.

Materi Pelatihan dalam kegiatan webinar ini diantaranya adalah tips memilih jurnal elektronik serta tata cara melakukan publikasi pada jurnal elektronik. Dalam materi tips memilih jurnal, peserta dibekali informasi tentang hal-hal yang harus diperhatikan dalam memilih jurnal serta mengetahui aturan aturan yang diterapkan setiap jurnal. Pada kegiatan ini instruktur mencontohkan laman jurnal yang ada dan memberikan penjelasan umum terkait informasi yang ada pada laman jurnal, diantaranya focus and scope, author guidelines, indeksasi jurnal, article proccesing charge, akreditasi jurnal, dan jadwal terbit. Dalam materi tata cara melakukan publikasi, peserta dilatih melakukan publikasi yang meliputi cara submit, cara revisi artikel hasil review, dan melakukan proses copyedit. 


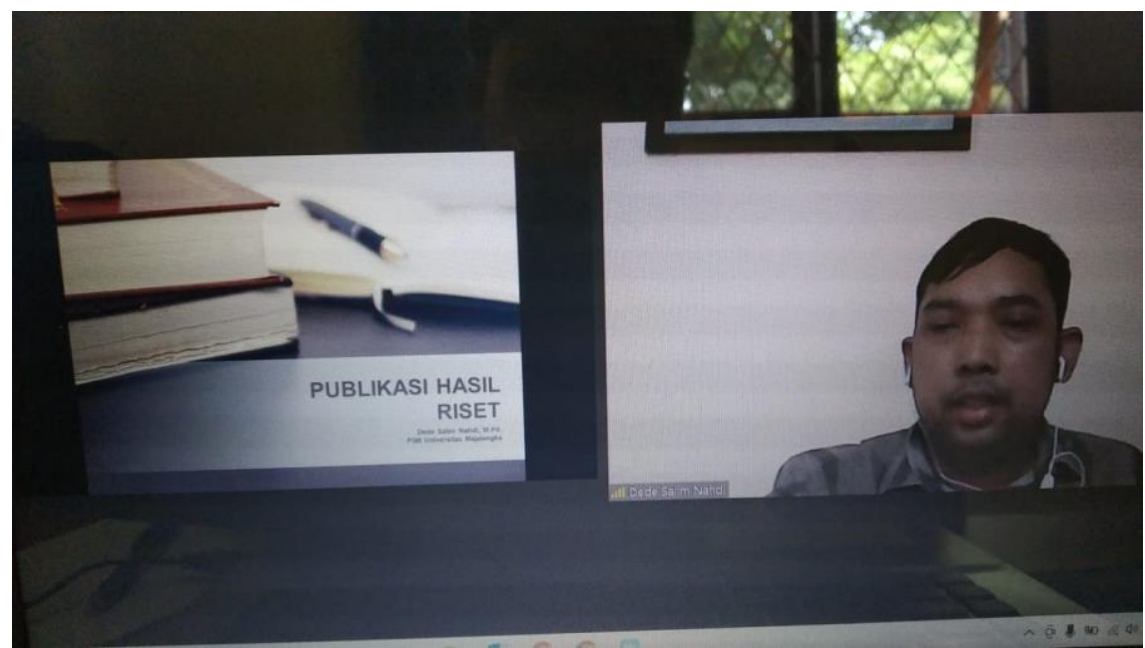

Gambar 1. Pemaparan materi oleh narasumber

Evaluasi kegiatan dilakukan dengan tanya jawab dan pemberian kuisioner kepada guru-guru peserta pelatihan untuk melihat sejauh mana tanggapan peserta terhadap kegiatan yang telah dilakukan. Aspek yang ditinjau adalah tentang pendapat dan tanggapan peserta tentang pelaksanaan pelatihan publikasi karya ilmiah pada jurnal elektronik. Berdasarkan pertanyaan dari guru diketahui, sebagian besar guru belum memahami tentang memilih jurnal elektronik yang baik dan melakukan proses publikasi pada jurnal elektronik.

Hasil diskusi memperlihatkan bahwa guru sangat setuju dengan kegiatan pengabdian ini karena dengan adanya sosialisasi dan pelatihan tentang publikasi karya ilmiah dalam jurnal peserta jadi tahu seputar jurnal dan cara publikasinya. Selain itu, materi yang disampaikan mudah dimengerti dan mudah dipraktekan sendiri, waktu pelaksanaan kegiatan tidak mengganggu kegiatan belajar mengajar karena dilaksanakan ketika siswa telah selesai melakukan ujian. Di samping itu, peserta juga termotivasi dan tertarik untuk melakukan publikasi karya ilmiah dalam jurnal.

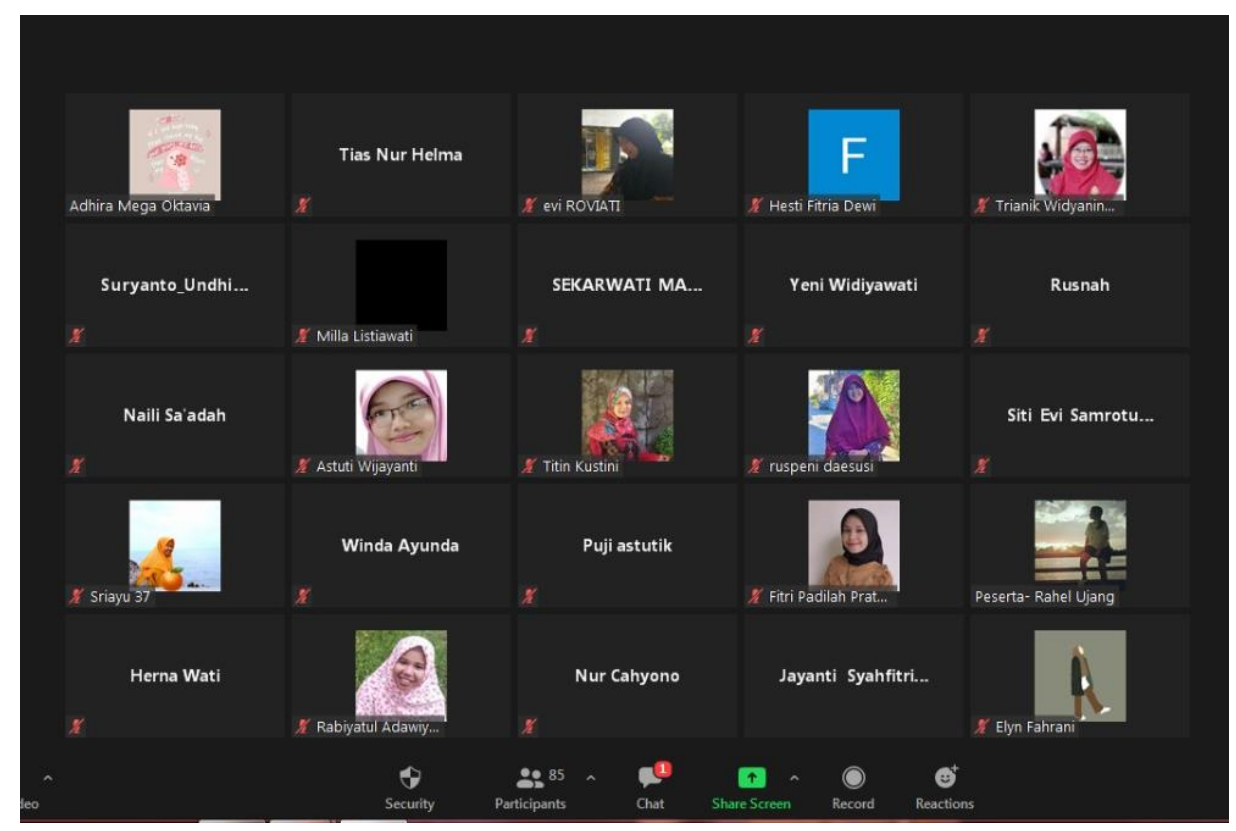

Gambar 2. Peserta webinar 


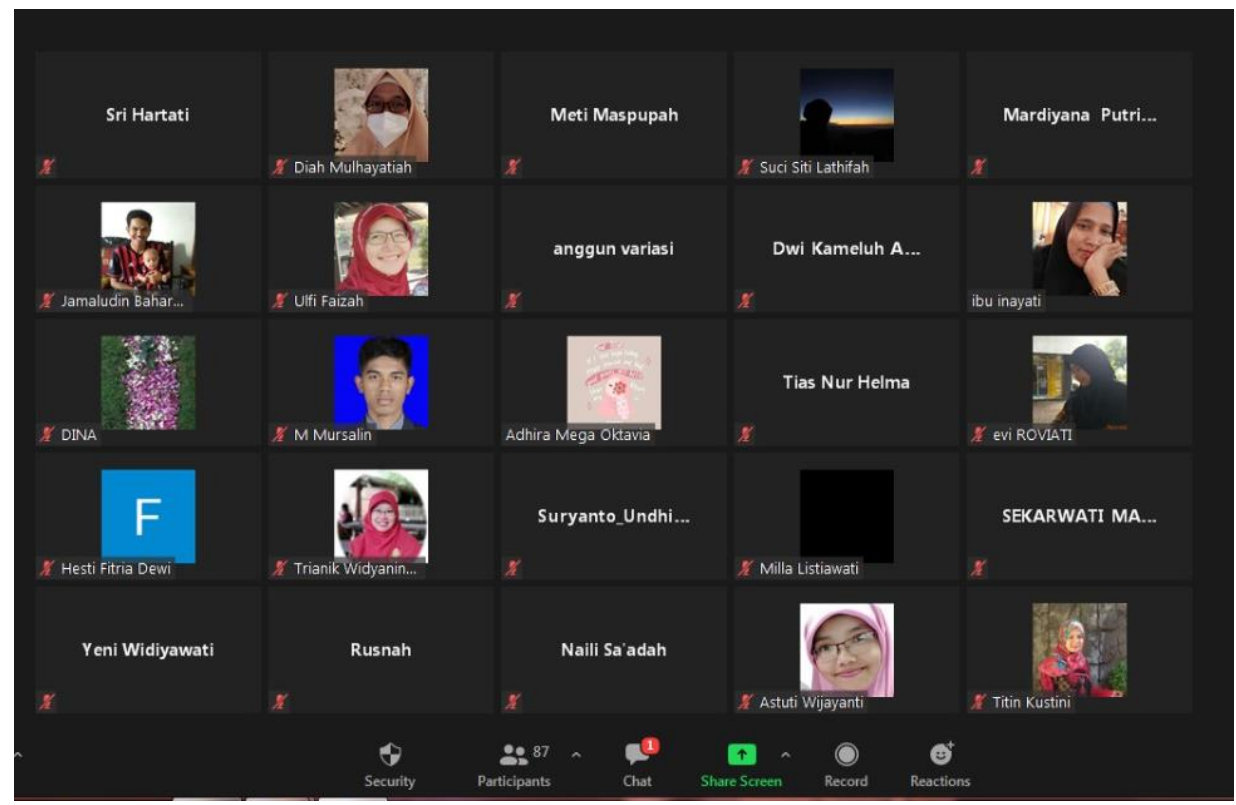

Gambar 3. Peserta webinar

Pelatihan guru mengenai publikasi karya ilmiah memang diperlukan untuk memberikan wawasan dan motivasi kepada guru. Program pelatihan dan pendampingan merupakan pelaksanaan program strategis untuk memberikan layanan pengembangan kompetensi guru. Selain itu, kegiatan ini merupakan kepanjangan tangan untuk mensosialisasikan ragam kegiatan pengembangan profesi kepada para guru di lapangan

Dari kegiatan pelatihan ini diperoleh hasil yang telah dicapai diantaranya: (1) Melalui kegiatan ini, mitra yakni guru dapat mengetahui hal-hal yang perlu diperhatikan dalam memilih jurnal yang tepat sebagai media publikasi karya ilmiahnya. Sehingga guru dapat menulis artikel ilmiah yang baik dan benar sesuai dengan kaidah-kaidah penulisan artikel ilmiah serta mampu memahami strategi-strategi agar artikel mereka dapat diterbitkan pada jurnal OJS yang dituju. Dengan kemampuan menulis artikel ilmiah yang baik, maka akan memudahkan bagi mitra sebagai calon author untuk dapat dengan mudah diterima naskahnya oleh jurnal yang dituju untuk diterbitkan; (2) Guru memliliki pengetahuan tentang sistem Online Journal System (OJS) dalam melakukan proses penerbitan jurnal yang dilalui dengan beberapa tahapan dari submit hingga terbit jurnal; (3) Pelatihan submit artikel ilmiah melalui OJS, setiap mitra memiliki akun author dan juga memberikan hasil kepada guru berupa pengetahuan serta keterampilan dalam melakukan submit artikel ilmiah melaui OJS.

\section{Kesimpulan}

Berdasarkan hasil yang diperoleh dalam kegiatan pengabdian menunjukan bahwa adanya peningkatan pemahaman para guru tentang publikasi karya ilmiah pada jurnal elektronik. Dengan demikian hasil yang diperoleh dianggap sesuai dengan target serta apa yang direncanakan. Dengan kegiatan ini diharapkan para guru peserta pelatihan termotivasi untuk melakukan publikasi dalam jurnal ilmiah sehingga terjadi peningkatan dalam profesionalismenya.

\section{Daftar Pustaka}

Al Idrus, S. W., Anwar, Y. A. S., Hakim, A., \& Saprizal, S. (2020). Penulisan Artikel Ilmiah Sebagai Upaya Peningkatan Profesionalisme Guru Kimia SMA di Kota Mataram. Jurnal Pengabdian Masyarakat Sains Indonesia, 2(1). 
Danim, Sudarwan. (2010). Profesionalisasi dan Etika Profesi Guru. Bandung: Alfabeta.

Gunawan, I. (2014). Metode Penelitian Kualitatif: Teori dan Praktik. Jakarta: PT Bumi Aksara.

Ilfiandra, I., Suherman, U., Akhmad, S. N., Budiamin, A., \& Setiawati, S. (2016). Pelatihan dan Pendampingan Penulisan Karya Tulis IImiah Bagi Guru SD. Jurnal Pengabdian Pada Masyarakat, 1(1), 70-81

Jabarnews. (2018). Guru Majalengka Dilatih Penulisan Karya I/miah. Retrieved from https://jabarnews.com/read/59566

Latiana, L. (2019). Peran Sertifikasi Guru Dalam Meningkatkan Profesionalisme Pendidik. Edukasi, 13(1).

Lestari, M., Faozanudin, M., Puspita, DR. (2018). Analisis Faktor-Faktor Yang Mempengaruhi Produktivitas Publikasi Ilmiah Guru PNS di SMP Negeri 1 Rembang dan SMP Negeri 3 Pengadegan Kabupaten Purbalingga. The Indonesia Journal of Public Administration. 4 (1). Hal 1-21.

Muhali, M., Asy'ari, M., Prayogi, S., Samsuri, T., Karmana, I. W., Sukarma, I. K., \& Hunaepi, H. (2019). Pelatihan Kegiatan Penelitian dan Penulisan Karya Ilmiah bagi Guru Madrasah Aliyah Negeri 3 Lombok Tengah. Abdihaz: Jurnal Ilmiah Pengabdian pada Masyarakat, 1(1), 28-36.

Mustofa, M. (2007). Upaya pengembangan profesionalisme guru di indonesia. Jurnal Ekonomi dan Pendidikan, 4(1), 17245.

Nidawati, N. (2020). Penerapan Peran Dan Fungsi Guru Dalam Kegiatan Pembelajaran. Pionir: Jurnal Pendidikan, 9(2).

Noorjannah, L. (2014). Pengembangan Profesionalisme Guru Melalui Penulisan Karya Tulis Ilmiah Bagi Guru Profesional Di SMA Negeri 1 Kauman Kabupaten Tulungagung. Jurnal Humanity. 10 (1). 97-114.

Rusdarti, R., Slamet, A., \& Prajanti, S. D. W. (2019). Pengembangan Keprofesian Berkelanjutan Dalam Pembuatan Publikasi Ilmiah Melalui Workshop Dan Pendampingan Bagi Guru Sma Kota Semarang. Rekayasa: Jurnal Penerapan Teknologi dan Pembelajaran, 16(2), 271-280.

Suandi, I. N. (2008). Gerakan Menulis Karya Ilmiah (Sebuah Upaya Peningkatan Profesionalisme Guru). Jurnal Pendidikan dan Pengajaran UNDIKSHA, 41(1), 510531.

Sumartini, S., Mulyani, M., \& Nugroho, B. A. (2019). Workshop Penulisan Karya Ilmiah Bagi Guru Sekolah Dasar Di Kabupaten Demak. Jurnal Puruhita, 1(1), 54-59.

Yolenta Owa. (2021). Upaya Peningkatan Kinerja Guru Melalui Teknik Lesson Study Secara Kolaboratif dan Rutin di TKK Negeri Harapan Bangsa Bajawa Kabupaten Ngada. Warta Pendidikan / E-Journal, 4(4), 13-19. 